\title{
AS RELAÇÕES ENTRE DISCURSO MIDIÁTICO E GEOGRAFIA ESCOLAR: UM DIÁLOGO POSSÍVEL
}

\section{THE RELATIONSHIPS BETWEEN MEDIA DISCOURSE AND SCHOOL GEOGRAPHY:}

\section{A POSSIBLE DIALOGUE}

\author{
Francisco Fernandes Ladeira ${ }^{1}$
}

Submetido em: 17/07/2019

Correções requeridas em: $14 / 09 / 2020$

Aprovado em: 16/09/2020

\section{RESUMO}

Compreender as diferentes linguagens utilizadas pelos meios de comunicação de massa é uma questão importante para a Geografia Escolar. Categorias-chave do pensamento geográfico - entre elas, território, paisagem e espaço - estão constantemente presentes em noticiários, filmes, documentários, seriados e programas de entretenimento de maneira geral. Nesse sentido, o presente artigo apresenta uma reflexão sobre as relações entre discurso midiático e processo de ensino-aprendizagem em Geografia na educação básica. Propõe-se a incorporação do material midiático em sala de aula não como mero recurso didático complementar, de caráter ilustrativo, mas como objeto de estudo a ser sistematizado em seu conteúdo discursivo.

PALAVRAS-CHAVE: Ensino de Geografia. Mídia. Discurso. Decodificação.

\section{ABSTRACT}

Understanding the different mass media's language is an important issue for School Geography. Key-Categories of the Geographical Thought - between them, territory, landscape and space - are constantly presents in news, films, documentaries, serials and entertainment programs in general. In this sense, the present article presents a reflection on the relations between media discourse and the teaching-learning process in Geography in basic education. We propose the incorporation the media's material in the classroom not as a mere complementary didactic resource, of an illustrative character, but as an object of study to be systematized in its discursive content.

KEYWORDS: Geography teaching. Media. Discourse. Decoding.

\footnotetext{
${ }^{1}$ Mestre em Geografia pela UFSJ. Articulista do Observatório da Imprensa. Professor de Geografia do IFES - Campus Vitória. Instituto Federal do Espírito Santo (IFES). 


\section{APRESENTAÇÃO DO TEMA}

Nestas primeiras décadas do século XXI, recebemos em nossas casas grande número de informações midiáticas sobre temáticas que, em grande parte, também estão presentes no currículo da Geografia Escolar, como globalização, conflitos geopolíticos, aquecimento global, problemas urbanos, fontes de energia, crescimento demográfico e desenvolvimento sustentável. Desse modo, com a evolução dos meios de comunicação de massa, passamos a ter uma nova forma de linguagem interagindo com o ambiente de sala de aula e promovendo intensos processos comunicativos e troca de significados entre professores e alunos.

Diante dessa realidade, autores como Ladeira e Leão (2018), Leão e Carvalho Leão (2008), Souza e Queiroz (2012), Guimarães (2016) e Pontuschka (2001) afirmam que a utilização de diferentes linguagens midiáticas na Geografia (documentários, filmes, programas de televisão, textos de jornais, revistas e internet) consiste em importante ferramenta pedagógica, podendo auxiliar na compreensão e crítica da produção do espaço.

Entretanto, é preciso que o uso do material midiático em sala de aula supere a posição de mera ilustração didática, e a reflexão de professor e alunos tenha como ponto de partida o conhecimento geográfico. Não obstante, pesquisas empíricas (LEÃO, 2003; LADEIRA e LEÃO, 2018) atestaram que muitos professores de Geografia incorporam o texto midiático em suas aulas sem ressignificá-los, como meros recursos pedagógicos ilustrativos, fator que acaba comprometendo o seu valor como material pedagógico. A linguagem midiática, além de ser um elemento de transmissão de ideias ou de informações, se configura, também, como um poderoso recurso de estabelecimento de imagens que, no conjunto, podem influenciar o posicionamento ideológico daqueles que decodificam a sua mensagem. P o r t a n to, espera-se que a sala de aula seja um espaço privilegiado para a construção do conhecimento que possa permitir a emancipação da palavra e a transformação do aluno em um interlocutor crítico capaz de estabelecer a conexão entre identidade, linguagens e signos, deixando de ser um usuário passivo para se transformar em enunciador/ enunciatário das informações recebidas.

Nesse sentido, o presente artigo apresenta uma reflexão sobre as relações entre discurso midiático e processo de ensino-aprendizagem em Geografia na educação básica. Para tanto, propõe-se a incorporação do material midiático em sala de aula não como mero recurso didático complementar, mas como objeto de estudo a ser sistematizado em seu conteúdo discursivo.

\section{MATERIAL MIDIÁTICO: POSSIBILIDADES PEDAGÓGICAS}

Grande parte dos conteúdos disponibilizados pelos meios de comunicação de massa aborda questões relacionadas à Geografia como globalização, conflitos geopolíticos, aquecimento global, problemas urbanos, fontes de energia, crescimento demográfico e desenvolvimento sustentável, entre outros temas. Em suma, a mídia pode representar um poderoso concorrente discursivo da ciência geográfica.

A Geografia, na mídia, torna-se espetáculo. [...] Essa Geografia, amplamente disseminada pela mídia por meio de imagens, textos e peças publicitárias, serve a um mercado com propósitos definidos e atinge toda a humanidade, uma humanidade que vive em uma época na qual se tem pressa para pensar, ler, ver e consumir. [...] A disseminação dos saberes geográficos pode ser vista nas diferentes mídias. Nunca houve tantas publicações envolvendo a descrição de paisagens e lugares que se intitulam "publicações geográficas". As imagens cartográficas proliferam-se nos mais diferentes meios: jornais, revistas, televisão etc. $\mathrm{Na}$ Televisão, verifica-se a existência de programas destinados a explorar características específicas do espaço geográfico, fazendo um levantamento de tudo o que consideram como sendo "a Geografia do lugar abordado", que pode ser a China, a savana africana, o deserto australiano, o Pólo Norte, ou a vida selvagem da Amazônia. Existem, também, canais, através da TV por assinatura, que se dedicam especialmente a essa temática (GUIMARÃES, 2007, p. 59-61).

Sob o aspecto pedagógico, a mídia, sobretudo a televisão, tem o poder de trazer para a sala de aula 
a representação de diferentes espaços mundiais (LEÃO e CARVALHO LEÃO, 2008, p. 14). Thompson (1998) afirma que as imagens e textos midiáticos criaram uma "mundialidade mediada", responsável por alterar nossa compreensão de mundo fora do alcance de nossa experiência pessoal. Desse modo, os horizontes espaciais de nossa compreensão se dilatam vertiginosamente, uma vez que eles não precisam mais estar presentes fisicamente aos lugares onde os fenômenos observados acontecem.

Diante dessa realidade, as instituições de ensino não devem tentar dissipar por completo a presença da mídia na vida do cidadão comum, tampouco demonizar os meios de comunicação de massa, mas concebê-los como fenômenos inerentes às sociedades contemporâneas, que podem ser lidos criticamente e transformados em fontes de aprendizado para discentes e docentes.

O contato dos alunos com o material produzido pela mídia traz uma oportunidade para que eles percebam paisagens que estão além de seus cotidianos, conheçam as principais questões ambientais, se conscientizem sobre os principais urbanos, como vivem os habitantes de outros países e possam ter parâmetros de comparação para refletir sobre suas próprias condições de vida.

Ao utilizar imagens, vídeos, obras de arte ou um texto literário, pode se estimular o aluno a compreender os conceitos geográficos, considerando não só a capacidade cognitiva, mas aspectos afetivos e culturais, potencializando a aprendizagem significativa. É importante entender que essas linguagens não são instrumentos ou meras ferramentas, mas são utilizadas como propostas voltadas para o processo de aprendizagem e para a ampliação do capital cultural do aluno (CASTELLAR e VILHENA, 2010, p. 8-9).

Martínez Sánchez (1999) defende que a escola propicie uma formação adequada para que os cidadãos sejam capazes de analisar e fazer suas próprias interpretações sobre as informações que os meios de comunicação oferecem. Para isso, são imperiosos três objetivos básicos: formar para os meios, formar com os meios e formar a partir dos meios.

Formar para os meios consiste em realizar uma incorporação dos meios no ensino formal e colocar à disposição dos estudantes as condições ideais e os instrumentos necessários para que possam fazer uma leitura completa e pessoal dos conteúdos vinculados pela mídia. Já formar com os meios significa, principalmente, que a introdução de um determinado meio seja feita em função de uma elaboração maior e mais ampla, que the confira sentido e significado.

Sendo assim, a utilização do material midiático deve ser uma resposta a um problema didático detectado pelo educador. Por fim, formar a partir dos meios representa entrar nas peculiaridades técnicas, compreender as entrelinhas e desvelar os objetivos ideológicos e comerciais dos meios de comunicação de massa.

Ainda segundo Martínez Sánchez, o fato de se acrescentar um meio de comunicação à prática docente não outorga a ele um caráter didático. O professor deve refletir sobre sua realidade educativa concreta e quais são suas reais necessidades em relação a esse meio, o que busca nele e que lugar ocupará dentro de sua dinâmica pedagógica. "Isso significa que o meio não pode ou não deve ser empregado pelo professor na forma que the chega às mãos" (MARTíNEZ SÁNCHEZ, 1999, p. 64).

Trabalhar com diferentes tipos de mídias requer um planejamento bem definido, objetivos claros, vocabulário adequado e metodologias de ensino pertinentes que superem a simples transmissão de informação. Também é fundamental levar em consideração a interferência de fatores externos à produção do conhecimento como aspectos subjetivos de alunos e professores, condições estruturais da escola, contradições de cada realidade e a diversidade de classes, gêneros e faixas etárias apresentada pelo corpo discente, pois "as condições materiais em que e sob que vivem os educandos thes condicionam a compreensão do próprio mundo, sua capacidade de aprender, de responder aos desafios" (FREIRE, 2011, p. 134).

Desse modo, a situação e o contexto de aprendizagem devem ser estimulantes, atrativos, significativos e articulados com a apropriação e o uso do conhecimento. De acordo com Samuel Pfromm Netto (1998, p. 19), para que toda a vasta gama de materiais e equipamentos audiovisuais mobilizados na educação produzam resultados que se traduzam em aprendizado efetivo, de qualidade satisfatória e duradoura, é necessário que o professor apresente as seguintes 
competências: a) dominar os múltiplos processos e meios técnico-artísticos necessários ao planejamento e à produção de materiais educativos; b) discernir a qualidade do conteúdo a ser ensinado/aprendido; e c) reconhecer os processos sobre como os seres humanos aprendem, retêm e aplicam o que aprenderam.

Como a linguagem da mídia oferece diferentes oportunidades educacionais, espera-se que o professor possua noções satisfatórias sobre as possibilidades e restrições dos suportes midiáticos que pretende utilizar em sala de aula, levando em consideração os elementos básicos do processo de comunicação - o saber, o discurso, as imagens e a escrita - e suas inter-relações com fatores políticos, econômicos e tecnológicos (PARRY, 2012). Além do mais, o material midiático, incorporado à prática docente, não pode se limitar a um mero repassador de informações, mas se constituir em um objeto de estudo a ser sistematizado e ressignificado em sala de aula.

A força de penetração dos meios de comunicação junto às mais variadas camadas da população deveria fazer com que todo educador procurasse analisar e refletir melhor sobre o papel destes veículos a fim de que pudesse aproveitar melhor esta força poderosa para disseminar informações e criar hábitos em termos educacionais. [...] A escolha do meio adequado vai depender das características dos alunos, dos estímulos necessários para alcançar os objetivos desejados, dos métodos instrucionais a serem empregados e das condições ambientais. [...] Considerando a influência dos meios de comunicação de massa na formação de hábitos, uma das tarefas mais importantes de pedagogos e professores nos dias de hoje é utilizá-los, cada vez mais, nas escolas (MATTOS, 2009, 191-192).

Para Fischer (2007, p. 296) conhecer os processos de produção de materiais audiovisuais, as diferentes formas de recepção e uso das informações, narrativas e interpelações de programas de televisão, filmes, vídeos e jogos eletrônicos são práticas eminentemente pedagógicas e indispensáveis ao professor contemporâneo. Trata-se, portanto, de apreender cada artefato midiático de maneira holística, em sua concretude histórica, comunicacional, mercadológica, política, e também como material que é produzido e veiculado de acordo com um determinado aparato técnico que, por si mesmo, também produz efeitos em nós.

\section{TEXTOS MIDIÁTICOS E ENSINO DE GEOGRAFIA}

Enquanto disciplina escolar, a Geografia oferece possibilidades didáticas de utilização e decodificação do material produzido pelos meios de comunicação de massa, pois várias categorias de análise inerentes à ciência geográfica como espaço, território, lugar, nãolugar, territorialidade e escalas estão constantemente presentes no vocabulário utilizado pela mídia e, assim, podem promover a interdiscursividade entre a linguagem jornalística e o conhecimento geográfico ensinado pelo professor em sala de aula.

Pontuschka (2001) afirma que a introdução de diferentes linguagens midiáticas na Geografia Escolar, caso o seu uso como mera ilustração seja superado, auxilia na compreensão e crítica da produção do espaço. Desde que o referencial para a sua reflexão seja o conhecimento geográfico, o professor pode transformar qualquer texto midiático em material útil para a sua prática didática, pois não é a mensagem contida na mídia que dá sentido ao ensino da Geografia, mas o contrário. As instituições escolares devem estar preparadas para incorporar a linguagem dos grandes meios de comunicação, servindo-se dela sem ser por ela dominada. Todavia, o educador não deve, simplesmente, desconstruir ou referendar as ideologias presentes na mídia.

É comum professores recomendarem aos alunos a leitura de jornais para que conheçam a "realidade" do que acontece no mundo. Essa sugestão sem algumas advertências produz efeitos negativos. Associar a informação da mídia à realidade faz crer na sua transparência, ou seja, na correspondência absoluta entre o texto, a foto ou a imagem e o fato a ser descrito (BARROS FILHO, 1998, p. 55 apud LEÃO, 2003, p. 70).

Desse modo, seria proveitoso conhecer a 
linguagem midiática para que professores e alunos sejam interlocutores ativos e não receptores passivos dos discursos difundidos pelos meios de comunicação de massa.

Nesse momento de seleção do material midiático, o professor tem que saber qual Geografia pretende ensinar. A que busca elucidar os fatos, ao se estabelecerem causas e consequências? Ou a que se apoia no material produzido pela mídia para vender uma ideia ou concepção de mundo? $\mathrm{Ou}$, ainda trata-se apenas de usar o espaço da aula de Geografia para a exibição de um jornalismo espetáculo? Sem o espaço da ressignificação da linguagem midiática, a aula de Geografia serve de aluguel para o discurso da mídia; configura-se assim um processo de desterritorialização da Geografia. Resumidamente, isso significa que, na seleção e incorporação do material mediático, o professor deve estar seguro do que pretende, ao ensinar Geografia (LEÃO e CARVALHO LEÃO, 2008. p. 42).

Assim como no senso comum, alguns textos midiáticos fazem uso das palavras "paisagem" e "natureza" como se fossem conceitos idênticos. Frequentemente, o termo "paisagem" é apresentado nos meios de comunicação de massa de uma maneira meramente descritiva, ressaltando apenas seus aspectos visíveis, amiúde como sinônimo de uma vista esteticamente apreciável, escamoteando assim os processos históricos, sociais e econômicos que estão por trás das constituições dos diferentes tipos de arranjos espaciais.

Nessa perspectiva, Pereira (1995) mostra que a mídia tem divulgado uma ideia de Geografia voltada essencialmente para a descrição, na qual se enfatizam os aspectos físicos e os dados gerais da população, criando imaginários populares que consideram como "geográficas" as descrições paisagísticas povoadas de vegetações, morros, rios, climas e eventualmente até algumas populações exóticas (por serem típicas do lugar). como a da descrição dos fenômenos, sobretudo físicos e paisagísticos, pode ser atestada pela proliferação de algumas revistas, autodenominadas como "geográficas", que apenas mostram paisagens muito bem ilustradas que se prestariam a uma análise geográfica mais aprofundada, mas que ali recebem um tratamento meramente descritivo. Outras publicações, como, por exemplo, o Almanaque Abril, apresentam como assuntos referentes à Geografia os itens 'relevo, vegetação, clima, ecologia, hidrografia, plataforma continental e ilhas oceânicas, e a presença brasileira na Antártica (PEREIRA, 1995, p. 68).

As seleções de determinadas paisagens pela mídia revelam quais tipos de representações os principais grupos de comunicação pretendem difundir sobre um país, região ou continente. Por causa dos lugarescomuns midiáticos, muitos alunos podem encontrar dificuldades em compreender a existência de bolsões de pobreza nos Estados Unidos e na Europa Ocidental ou que o continente africano também possui grandes centros urbanos e não apenas paisagens praticamente selvagens. Do mesmo modo, nas aulas de Geografia do Brasil, alguns estudantes associam o Nordeste, região marcada por grande diversidade natural, à Caatinga e ao clima semiárido ou o Norte do país à Floresta Amazônica e a rios caudalosos Por outro lado, Steinberger (2005) adverte que uma análise do discurso jornalístico que aborde suas fontes e condições de produção é importante para demonstrar os efeitos potenciais que a manipulação política de lugares e valores geográficos pode gerar na consciência dos imaginários sociais.

O jornalismo tem-se firmado como um dos mais poderosos campos em que os discursos sobre o mundo são produzidos e difundidos. A produção jornalística tem grande visibilidade pública, o que dá a esse campo condição singular, em relação aos outros campos, de impor e disseminar seu ponto de vista, seus referenciais, suas concepções de mundo. Analisar, portanto, esse campo, seu papel, seu funcionamento, suas práticas discursivas, explicações e visões de mundo constituem- 
se em tarefa importante na atualidade. Essa tarefa apresenta-se imprescindível para o ensino de Geografia, cujo objetivo é ensinar e possibilitar aos jovens e às crianças conhecer e interpretar o mundo (GUIMARÃES, 2006, p. 84).

É fundamental entender o processo de construção da notícia, pois a mídia possuí uma linguagem própria e a informação passa por várias mediações, desde a fonte até o receptor. Não obstante, a realidade é demasiadamente complexa para ser compreendida e explicada por apenas um campo do conhecimento. Para Hissa (2006), não existe uma "geografia pura", que possa desenvolver uma leitura plena dos processos espaciais independente de outras disciplinas. Apesar de as categorias de análise da ciência geográfica ser elementos essenciais para decodificar os diferentes tipos de discursos presentes na mídia, a utilização do material midiático em sala de aula requer abordagens plurais, complexas e transdisciplinares, que extrapolem os limites da Geografia Escolar, recorrendo constantemente a conhecimentos inerentes à História, Semiologia, Linguística, Psicologia, Comunicação, Antropologia, Sociologia, Ciência Política e Filosofia, para que comuniquem entre si, sem operar, no entanto, a redução de seus pressupostos fundamentais. É preciso saber ler a mídia, desvendar seus possíveis mecanismos manipuladores e os jogos de interesses econômicos que estão por trás do seu funcionamento, pois notícias são mercadorias como quaisquer outros bens de consumo. Palavras podem ser poderosos instrumentos de sensibilização e persuasão. Morin (1999) afirma que, na análise de um discurso não podemos isolar uma palavra, uma informação; é preciso ligá-la a outras, mobilizarmos o nosso saber e nossa cultura para chegarmos a um conhecimento apropriado e oportuno da mesma. Para ter sentido, a palavra necessita do texto, que, consequentemente, necessita do contexto no qual se enuncia. Nos discursos midiáticos, as escolhas de um determinado verbo ou de uma conjunção não são feitas por simples escolhas gramaticais, mas ideológicas. Um veículo midiático geralmente está a serviço de poderosas forças econômicas. Desse modo, é imprescindível desvelar os contextos de produção, interesses corporativos e jogos de poder que estão por trás dos discursos midiáticos. Um determinado enquadramento da realidade, o repertório lexical e as cargas semânticas que as palavras assumem nos discursos midiáticos fornecem importantes referenciais para encontrar possíveis práticas manipuladoras.

Diante dessa realidade, o sujeito que possui o mínimo conhecimento sobre o maquinário midiático, seleção de pautas (agenda-setting) e o contexto de construção da notícia (newsmaking) dificilmente será um alvo vulnerável para o pensamento dominante, pois conhecer os códigos linguísticos utilizados pelo emissor amplia as possibilidades de leitura do codificador. Em outros termos, dominar os mecanismos que regem a linguagem dos meios de comunicação de massa significa não incorrer no risco de ser por eles dominados.

\section{CONSIDERAÇÕES FINAIS}

A mídia procura aparentar imparcialidade, porém o repertório lexical por ela utilizada, a concessão de mais espaço a uma notícia em detrimento de outras, a maneira como é desenvolvida a cobertura de um acontecimento, a escolha do título de uma matéria e os critérios para o posicionamento de uma foto são exemplos de posturas que deixam transparecer posicionamentos ideológicos e eliminam a ideia de uma possível neutralidade da informação. Os grandes grupos de comunicação geralmente servem aos interesses de governos ou das empresas que os financiam. Ao contrário do preconizado pela "Teoria do Espelho", as coberturas jornalísticas não são reflexos fidedignos da realidade, capturados objetivamente, sem nenhum tipo de interferência do olhar do observador. Os noticiários são construções sociais sobre a realidade que ganham materialidade através de determinadas práticas discursivas. Valores subjetivos e a maneira de conceber o mundo do produtor de uma notícia certamente vão influenciar, de alguma maneira, a construção de seu texto.

É importante que o professor tenha em mente que a utilização do material midiático em sala de aula precede da compreensão de que a mídia possui poderosos instrumentos para difundir a sua linguagem, com profissionais cada vez mais bem preparados e equipamentos sofisticados.

Portanto, sugerimos que o material midiático seja incorporado no ensino básico como se estivesse pronto e acabado ou tampouco o professor pode transferir para este recurso paradidático a tarefa de ensinar. Agindo 
dessa maneira, o docente pode levar o aluno a acreditar que o conteúdo vinculado pelos meios de comunicação, por si só, possui legitimidade como portador do conhecimento. Por outro lado, as instituições escolares podem se tornar instâncias privilegiadas para a formação de cidadãos críticos em relação à mídia. Nesse sentido, é imprescindível que os alunos desenvolvam capacidades intelectuais básicas para processar e refletir sobre o que se lê e assiste nos principais veículos de comunicação. Entende-se assim que cabe ao educador promover a ressignificação do discurso midiático em sala de aula e orientar seus alunos no gerenciamento das informações que estão disponíveis nos principais veículos de comunicação, pois tão importante quanto o acesso à pluralidade de informações disponíveis é acionar os atributos intelectuais indispensáveis para selecioná-las, processá-las, interpretá-las e transformá-las.

Desse modo, um dos grandes desafios para os professores neste início de século $\mathrm{XXI}$ é contribuir para que, no tocante aos conhecimentos geográficos, o senso de julgamento de seus alunos não fique refém de um enquadramento midiático que busca explicações simplórias para as mais complexas temáticas. Para dinamizar o processo de ensino-aprendizagem, adaptando a prática pedagógica às demandas da contemporaneidade, não basta equipar as escolas com televisões, computadores, aparelhos de vídeo, projetores multimídias (data-shows), etc. É preciso superar a visão instrumental e mecanicista sobre a incorporação de tecnologias na educação, levando em consideração, sobretudo, o fator humano.

O uso de diferentes tipos de mídia é inócuo caso o professor não possua a formação, preparação e conhecimento adequados para trabalhá-las em sala de aula. Não adianta incorporar novas tecnologias nas instituições escolares se as práticas pedagógicas continuam obsoletas e não dialogam com os alunos.

As tecnologias da informação e comunicação não substituem o professor, mas ampliam sua voz e suas ações. É o conhecimento científico que irá conferir ao material midiático uma nova função, permitindo que os alunos tenham condições de atribuir novos significados às mensagens veiculadas na mídia.

Nesse sentido, introduzir no currículo escolar tópicos de uma consistente "pedagogia crítica da mídia" é um dos pressupostos fundamentais para construir um sistema de ensino que possa contribuir efetivamente para o pleno exercício da cidadania. Além de educarem com a utilização das diversas linguagens midiáticas em sala de aula, os docentes também devem, sobretudo, "educar para a mídia". Isso significa estudar a mídia e suas mensagens da mesma forma que se estudam as disciplinas propedêuticas, ou seja, ensinar o domínio da linguagem midiática da mesma forma que se ensina o domínio da linguagem escrita para assim utilizá-la da forma mais abrangente possível.

Baseado nos textos referidos neste artigo, consideramos que tal prática poderá contribuir para forjar nos estudantes a passagem de uma consciência ingênua para uma consciência crítica que permita reconhecer, além das intenções explícitas, as possíveis intenções implícitas que são vinculadas nos diferentes tipos de mídia.

\section{REFERÊNCIAS}

BACCEGA, Maria Aparecida. Meios de comunicação na escola. Comunicação \& Educação. São Paulo, v. 25, p. 7-15, set./dez. 2002.

BARROS FILHO, Clóvis de. Revista Educação, abril de 1998. In: LEÃO, Vicente de Paula. O uso da mídia no ensino da geografia na educação básica. Dissertação (Mestrado em Geografia) - Universidade Federal de Minas Gerais - UFMG, Belo Horizonte, 2003.

BRUNET, R. et al. Territoire et identité. Paris: Centre Nationale de Récherche Cientifique, 1992.

CALLAI, Helena C. In: PONTUCHKA, Níbia Nacib et al. Geografia em perspectiva. São Paulo: Contexto, 2006.

CASTELLAR, Sônia; VILHENA, Jerusa. Ensino de geografia. São Paulo: Cengage Learning, 2010.

CASTELS, Manuel. A sociedade em rede. São Paulo: Paz e Terra, 1999.

CLAVAL, Paul. O território na transição da pósmodernidade. Universidade de Paris-Sorbonne. 1996. Disponível em: http://www.uff.br/geographia/rev_02/ paul\%20claval.pdf. Acesso em: 16 fev. 2018.

FISCHER, R. M. B. Mídia, máquinas de imagens e 
práticas pedagógicas. Revista Brasileira de Educação, Rio de Janeiro, v. 12, n. 35, maio/ago. 2007.

GUIMARÃES, lara Vieira. Ensino de Geografia, mídia e produção de sentidos. Terra Livre, Presidente Prudente, Ano 23, v. 1, n. 28 p. 44-66 jan./jun. 2007.

(Org.). Espaço, tempo e

cultura midiática na escola: propostas para o ensino de Geografia. Curitiba: CRV, 2016.

Sobre os sentidos de ensinar e compreender o mundo - discurso jornalístico e ensino de Geografia. São Paulo, Programa de Pós-Graduação da Faculdade de Educação da Universidade de São Paulo (Tese de Doutorado), 2006.

HISSA, Cássio E. V. A mobilidade das fronteiras: inserções da geografia na crise da modernidade. Belo Horizonte: UFMG, 2006.

LADEIRA, Francisco Fernandes; LEÃO, Vicente de Paula. A influência dos discursos geopolíticos da mídia no ensino de Geografia: práticas pedagógicas e imaginários discentes. Curitiba: CRV, 2018.

LEÃO, Vicente de Paula; CARVALHO LEÃO, Inêz Aparecida de. Ensino de Geografia e Mídia: linguagens e práticas pedagógicas. Belo Horizonte: Argvmentum. 2008.

LEÃO, Vicente de Paula. O uso da mídia no ensino da geografia na educação básica. Dissertação (Mestrado em Geografia) - Universidade Federal de Minas Gerais UFMG, Belo Horizonte, 2003.

MARTÍNEZ SÁNCHEZ, F. Os meios de comunicação e a sociedade. In: Mediatamente: televisão, cultura e educação. Brasília: SEED/MEC, 1999.

MATTOS, Sérgio. O contexto midiático. Salvador: Instituto Geográfico e Histórico da Bahia, 2009.

MORIN, Edgar. Da necessidade de um pensamento complexo. In: MARTINS, F. M.; SILVA, J. M. (Orgs.).

Para navegar no século $\mathrm{XXI}$ : tecnologias do imaginário e cibercultura. Porto Alegre: Sulina, 1999. p. 19-42.

PARRY, R. A ascensão da mídia: a história dos meios de comunicação de Gilgamesh ao Google. Rio de Janeiro: Elsevier, 2012.

PEREIRA, D. Geografia escolar: conteúdos e/ou objetivos. Caderno Prudentino de Geografia Geografia e ensino, Presidente Prudente, AGB, n. 17, p. 62- 74, 1995.

PFROMM NETTO, Samuel. Telas que ensinam: mídia e aprendizagem do cinema ao computador. Campinas: Editora Alínea, 1998.

PONTUSCHKA, Nidia N. A geografia: Pesquisa e ensino. In: CARLOS, A. F. A. (Org.). Novos Caminhos da Geografia. São Paulo: Contexto, 2001. p. 111-142.

SOUZA, C. R. F.; QUEIROZ, A. M. D. A utilização dos meios de comunicação no ensino de Geografia. Revista Eletrônica Geoaraguaia, Barra do Garças, v. 2, n.1, p 62 - 85, jan./jul. 2012.

Disponível em: http://revistas.cua.ufmt.br/geoaraguaia/ index.php/geo/article/view/15. Acesso em: 17 fev. 2019.

STEINBERGER, Margareth Born. Discursos geopolíticos da mídia - jornalismo e imaginário internacional na América Latina. São Paulo: FAPESP, EDUC, CORTEZ, 2005.

THOMPSON, J. B. A mídia e a modernidade: uma teoria social da mídia. Petrópolis: Vozes, 1998. 